\title{
4. Re-thinking the social documentary
}

\author{
William Uricchio
}

\begin{abstract}
This chapter reflects on how people actively engage with interactive documentaries and how this constitutes a shift in audience participation. As a playful format, interactive documentaries invite viewers to also become creative participants. The author makes a convincing case for the civic potential of allowing viewers to play with the documentary film format, foregrounding the interactive documentary as a potent challenger to its traditional, linear, and author-driven counterpart. He speaks in this context of a 'producerly' audience that has an active input in the documentary textual interactive system. Uricchio speaks of interactive documentaries as a new media format, that does not so much replace existing, more hieratically structured media formats, but rather can exist alongside them as a participatory alternative.
\end{abstract}

Keywords: Interactive documentary, audience participation, producerly audience, playful media formats

It is happening again. The documentary, long underappreciated for its transformational impact on film form, is again offering new ways of representing and intervening in the world. Only this time, rather than simply using new techniques to represent social change, the documentary form is itself the subject of social and technological change. Documentary marks the place where our representational endeavors come face-to-face with reality. Little wonder that Vertov's attempts to position film as part of a social network remain so relevant, and that Direct Cinema and Cinema Verite's efforts to redefine the filmmaker-subject relationship had such a large impact (Singer 1987; Saunders 2007). Today, at a moment when locationaware mobile HD video cameras are nearly ubiquitous, where networked computers have broken the distribution bottleneck, and where game play,

Glas, R., S. Lammes, M. de Lange, J. Raessens, and I. de Vries, eds. 2019. The Playful Citizen. Civic Engagement in a Mediatized Culture. Amsterdam: Amsterdam University Press. DOI: $10.5117 / 9789462984523 / \mathrm{CHO} 4$ 
crowd-sourcing, and the social turn have redefined media practice and enabled widespread participation, documentary makers have been quick to respond. This chapter will explore the implications of these new voices, of the new, playful, interactive organizational logics and the new social and political enablement of the documentary form.

First, a few words about the stakes of change. As will be discussed, the ongoing transformation in documentary promises to empower new voices, encouraging 'the people formerly known as subjects' to participate in their own representation and have a hand in shaping their texts (see Lessig 2015, 37). It engages its users in interactive environments, offering opportunities to interrogate, explore, and comment upon ideas. Moreover, it enables global access, is available anytime, and is actively pushed through social recommendation networks. Still too emergent to be 'hard-baked' into orthodox practice, fixed definition, or even a broadly agreed upon agenda, I shall refer to this direction as interactive documentary, including within it not just non-linear textual structures that must be navigated by the user, but location-based and crowd-sourced documentaries as well, since these, too, belie fundamental forms of interaction with text, place, and public. ${ }^{2}$

In the pages ahead, I would like to explore developments in this sector, describing some of their key attributes, locating the 'new' within the historical practices from which they have emerged, and considering their challenges to our inherited notions of narrative and engagement. Particularly in this last regard, the narrative potentials of play will loom large, offering useful ways to reconsider the operations — and implications —of interactive documentary.

The digital dynamics underlying the interactive documentary (Nichols 1991; Galloway, McAlpine and Harris 2007; Aston and Gaudenzi 2012) are familiar, for we have seen them ripple through the music industry, take form in phenomena such as Wikipedia, and re-shape the nature of political campaigns. Thanks to networked digital technologies, the old divides between producers and consumers, between experts and the crowd, between the center and the margins, have weakened, taking new and sometimes unfamiliar forms. At a moment when Moore's Law continues its geometric progression of ever more powerful (and even cheaper) processing capacities, consumers now have easier access to audio and video equipment that less than a decade ago was limited to professionals. In 2013, YouTube users

1 Title of a public conversation held by Kat Cizek and Gerry Flahive, 23 October 2012, at MIT's Open Documentary Lab.

2 Other terminology includes i-Docs and web docs. 
were posting over 72 hours of video to the site every minute; and Facebook essentially required its over one billion active users to construct multimedia, autobiographical timelines on their pages, assembling their photos and video clips, geo-locative maps, links, and diary entries. ${ }^{3}$ Both of these examples testify to active popular engagement with digital media production, and while non-fiction is amply evident on YouTube, Facebook has managed to draw its users into the production of something that might reasonably be termed autobiographical mini-documentaries. Profiles are shaped, updated with representations of recent activities, and even augmented by others through 'tagging' functions. While these carefully curated assertions of self may seem rather minimal as documentaries, that over one billion people have sorted out how to construct and navigate them, as they seek to present themselves and keep up with their friends, suggests that the move to participation in the interactive documentary may be far less radical than mainstream linear film and video-makers and scholars might assume.

These developments underscore just how widespread public embrace of digital audio-visual production tools and assembly processes have been. They also reveal considerable levels of social exchange and collaboration and they point to the emergence of new collectivities of social networks unfamiliar to our scholarly traditions. And yet, we inhabit a moment of 'disconnect.' From the perspective of the dominant film and television industries, these widespread activities seem largely peripheral... even insignificant. Box office and television viewing rates remain healthy, and the industry's biggest worries are about how to coordinate content and audiences across multiple media platforms, how to defend their market share against erosion from the game industry, and how to curb piracy. Generally, with the exception of fast-growing interest in the 'second screen,' they have not expressed much curiosity about these new forms of production. When they have, it has either focused on their marketing potential, or given voice to their fears regarding the disruptive potentials of interactive storytelling techniques.

And yet one might argue, as does Henry Jenkins and his colleagues (Jenkins, Ford, and Green 2013), that even in the domain of quotidian media consumption, we see signs not just of an active, but of a 'producerly' public - one that contributes to the textual ecosystem, and one that knows

3 Since then, these numbers have grown exponentially; in September 2016, Youtube statistics sites reported a 416 per cent increase to 300 hours of video uploaded per minute (Statistic Brain 2016). According to a 2011 Pew Internet \& American Life Project study, "Fully $71 \%$ of online Americans use video-sharing sites such as YouTube and Vimeo, up from $66 \%$ a year earlier. The use of video-sharing sites on any given day also jumped five percentage points, from $23 \%$ of online Americans in May 2010 to 28\% in May 2011" (Moore 2011). 
how to pursue its interests across different media platforms and within interactive textual systems. Unlike the 'active' reader celebrated by a generation of literary theorists, where activity largely entailed creative textual engagements and interpretation, these readers take a hand in constructing their own texts from the building blocks and environments made available to them by what would normally be considered the 'producing' side of the equation. But the selection of which textual elements to include, their sequence and pacing, the ability in some cases to make external links or add comments, or in the case of games, to create new structures within a given environment, all transform the 'reader-producer' divide into something far more co-creative and collaborative on a textual level. The familiar interpretive level also comes into play, of course, arguably in a reconfigured form since it seems bound up in some of the processes that shape the text and in the condition of textual uniqueness (i.e. versions of texts specific to the individual navigator or player). This combination of textual assemblage and interpretation-required as we move across media platforms and channels - today seems just as routine as the activities of myriad Facebook and YouTube users, and, in its own way, just as productive.

\section{What's happening}

It is perhaps worth asserting that our history of the cinematic, in general, is rooted - in particular - in the documentary reflex. The first decade of filmmaking was dominated by actualité - phantom train rides, urban panoramas, parades, industrial processes, and the curiosities of the natural and man-made world - continuing a long fascination with the registration of visible evidence that can be found in photography, painting, and panoramic traditions (Uricchio 2011). But one might go on to argue, in terms that echo André Bazin, that the whole enterprise of photo-realist cinematography (as opposed to animation or abstraction), whether deployed for fictional or non-fictional purposes, derives its power from an assumed unproblematic relationship between the recording process and the real materialities of the pro-filmic event, even if, as is often the case with our dramatic fictional traditions, they are enveloped in the impossibility of magic. Much as media scholars can complicate and (rightly) undermine this view, our society's photo IDs and our justice system's reliance on surveillance footage and photographic evidence suggests how deeply rooted are these associations, and how much implication lies bound up within them. And these associations with the 'real,' in turn, help to fuel and support our engagement with 
fictional worlds. Like the young viewers of the Chinese magician in Vertov's Man with a Movie Camera (1929), we are fascinated by that-which-cannotbe-and-yet-seems-to-be. It remains to be seen, in an age of ever-intensifying digital effects, whether this cultural association will persist. ${ }^{4}$

Something transformative is taking place, and as usual in our media history, documentary is the canary in the coalmine. From its start, documentary has connected its audiences with the events of the world. It has offered a shifting metric of media's capacity to expose, represent, engage, and transform that world. And, if we take a broad view of documentary as a discursive mode that is not inherently bound to the motion picture, it has consistently been at the forefront of technological and stylistic change, using its tools to reveal the previously hidden, and to enable its viewers to see the familiar in new ways. ${ }^{5}$ The history of photography, and its modulations through stereoscopy, the panorama, and color, returns repeatedly and almost compulsively to depictions of the real as a benchmark of the latest technological turn's ability to 'capture' and document some once-missed aspect of the world. In the case of cinema, as well, not only was the first decennium dominated by the documenting impulse, but filmmakers' earliest uses of innovations such as the moving camera (panoramas and tracking shots of cityscapes), color (Pathé and Gaumont's nature films), and sound (Ruttmann's Melodie der Welt, 1929, and Vertov's Enthusiasm, 1931) explored the representational capacities by engaging the world around them.

Today's interactive documentary represents the most significant change in documentary form, mode of address and public reach since Direct Cinema and Cinéma Vérité. In the early $1960 \mathrm{~s}, 16 \mathrm{~mm}$ cameras and portable sound equipment enabled a new relationship between the filmmaker and the subject, resulting in new and distinctive styles of filmmaking that, thanks to television, found new markets and mass audiences just as theatrical outlets for documentary shorts began to fade from sight. Similarly, the interactive documentary arises from the affordances of today's networked digital technologies, redefines the line between makers and publics by enabling creative collaboration, results in new styles and approaches to argument and storytelling, and has the internet at its marketplace. We

4 To be clear, I do not wish to argue for the indexicality of the photographic image, nor to suggest that it is under siege in the digital era; rather, I am making a far softer claim regarding the formation and malleability of cultural associations.

5 See MIT's Open Documentary Lab (2018) for an overview of documentary precedents and contemporary practices. 
have seen exponential proliferation of these new documentaries in places like Canada's National Film Board and at the International Documentary Festival Amsterdam's DocLab; they have been pulling in impressive user numbers; they are showing signs of generating significant engagement and impact; and they are finding unexpected support and audiences in radio (Edmond 2015) and the online newspaper (The New York Times and Cizek's Highrise project, Cizek 2010).

For the record, fixed, linear filmmaking is neither dead, nor dying! It is alive, well, and wonderfully suited for many forms of argument and storytelling. However, its status and meaning are changing thanks to the interactive documentary's twofold impact. On one hand, as part of the larger 'user-generated' churn and breakdown of institutional filters represented by the internet, the rise of interactive documentaries re-contextualizes the status of institutionally produced linear stories. It renders linearity into a choice rather than the only option. On the other hand, it adds new perspective and technique to our expressive repertoire. It potentially maintains the complexity of issues that would be deformed by linearity; it enables new voices to be heard, to speak for themselves; and it enables users to find their own way and pursue their own interests in a story environment. The challenge is to know and be able to articulate which modes of documentation are most effective for a given task. And to the extent that communication is an underlying intent, it also means understanding the needs and tolerances of the audience. We inhabit a culture steeped in thousands of years of great 'linear' storytelling, and it is a tradition that will thrive. But a growing portion of the population also regularly uses interactive forms (games); they also routinely co-create (Facebook, YouTube); and for this population, interactive forms are also basic components of the culture.

As we look at contemporary culture, we can see that our old habits of sitting back and listening to a master storyteller can be complemented by collaborative efforts, as people navigate their way through interactive and location-based experiences, provide footage of their experiences and engage in more immediate ways than we have seen before. Notions of 'authorship, the stable text, and familiar divisions of labor between makers and viewers appear contested and uncertain. The instant temporalities of a connected culture have brought their own challenges, blurring the line between journalism and documentary, precisely at the moment when the institutional traditions behind these practices - the press, the cinema, television - themselves struggle for redefinition. We inhabit a moment of accelerated change, with all of the challenges to the old certainties and inherited traditions that this brings. 
Documentary, long identified with a form, with the linear' media of film and television, has been reborn as a mission, as a mode of engagement and interaction that is increasingly agnostic about form. The new documentary, with its challenges to established categories, practices, and behaviors, offers the tantalizing and terrifying possibilities of a terra incognita. At the same time, it offers a vantage point from which we can evaluate some of our assumptions and established practices. As it loosens its long association with cinematic and television exhibition (in part because of increasingly limited access to both screens), it increasingly appears on the web within multiple frameworks, including institutions not usually associated with documentary such as radio and press. This shift in locus encourages one to reconsider the taken-for-grantedness of those earlier venues, and to look for other documentary practices 'out there' that we have ignored or categorized out of existence. The changes that are increasingly evident in some sectors of documentary practice have challenged not only established notions of the text and authorship, they have also challenged the institutional assumptions behind documentary production and exhibition. As much as these moves offer promise and possibility, they also offer their share of challenges for the status quo, for our notions of use and impact, and for the very ways that we understand the meaning of the term 'documentary'.

\section{Playing with narrative}

Caspar Sonnen, director of Doclab — a festival program for new media within the International Documentary Festival Amsterdam (IDFA)—sometimes explains the difference between the traditional linear documentary and its interactive counterpart with the analogy of visiting a city. Nothing beats a great tour guide - someone knowledgeable about a location's history and meanings, someone who can direct our attention to the many things we would not have otherwise seen, and someone who can tell great stories. On the other hand, we have all had the experience of wandering through cities on our own, and when we do, whether armed with knowledge or not, we attend closely to our environment, keeping an eye on addresses and landmarks (in the hope we can find our way back!), following our interests and desires, making unexpected detours and discoveries, and creating our own stories. It is a useful analogy, as much because it makes clear that neither of these approaches is a threat or inherently superior to the other. They offer different affordances, suit different needs, require different stances. And, I would argue, they both offer narrative engagements. 
In his many lectures, MIT's Scot Osterweil uses a different analogy to make a related point. He distinguishes between the experiences of listening to a great storyteller and playing. In the first case, like the guided tour, we are led through experiences we would otherwise not have been privy to, abandoning ourselves to the craft of the narrator who leads us through the carefully plotted structure of the story (Marsh et al. 2011). In the case of play, ${ }^{6}$ something many of us abandoned relatively early in life, we imagine, and indeed, co-create a world and its rules, inhabit a character, and have a goal that we share with our playmates. But we have no idea, as we play, whether the good guys will win or not. We do not know what our fate will be. We simply improvise, inhabiting our characters and living the experience as it unfolds. Osterweil argues that this experience, like Sonnen's example of wandering, is profoundly narrative in character. The difference is that Osterweil's notion of play includes notions of character (such as invented, fictional notions), rules that we must adhere to, and an arbitrary goal. As the Creative Director of MIT's Education Arcade - a research lab that produces computer games for learning-Osterweil has a notion of play-as-narrative that unsurprisingly aligns with thinking in the game space, where story outcomes are unknown while the player navigates the diegetic world and its rules. ${ }^{7}$

This may seem an obvious point, but mainstream academic definitions of narrative draw a clear distinction between those events that, like the guided tour and told story, are 'narrated' versions of past or known events; and those that, like wandering on one's own or playing, are indeterminate and simply part of life's experiential flow. In a strict sense, no 'teller' of 'past events' means no narrative. And yet our experience while wandering or playing can seem as immersive, compelling, motivated, and coherent as any story; and in the case of play, it explicitly contains many of the same features (character, setting, rules, and an 'as if' fictional world). This latter point, of course, brings its share of complications to the documentary, but as I will suggest, it also offers important ways to rethink the place of

6 There are, of course, many varieties of play; Osterweil's reference is to character-based play.

7 The appearance of computer games around 1960, and particularly interactive fiction games such as Zork (Anderson, Blank, Lebling, and Daniels 1977), signaled a new turn in traditional narrative forms. Interactive literature, emblematized by the work of the Electronic Literature Organization founded in 1999, and interactive 'films', rooted, for example, in the work of MIT's Interactive Cinema Research Group in the late 1980 s (or even earlier, in Radúz Činčera's Kinoautomat at Expo 67), both attest to the relatively recent emergence of systematic developments in new forms of narrativity. However, as Whitney Anne Trettien reminds us, one can find much earlier precedents, in Trettien's case, going back to the eighteenth century (Trettien 2009). 
imagination in the domain of the non-fictional. But first, the problem of what constitutes a narrative.

The 1980 s saw both the rise of computer games and the emergence of alternate views regarding narrative. Three broad strategies can be distinguished. The first more or less maintains the existing definition of narrative ('the retelling of past events'), but redefines the player's activity, with some narratologists arguing that the wanderer's or player's consciousness serves as an implicit internal voice and thus provides the 'teller' to just-experienced events, which are technically 'past' by the time they are cognitively processed. A variation on this approach takes such challenges as the 'just-experienced' problem and the indeterminate nature of conclusions, arguing that the narrative is what is constructed retrospectively, after the process is completed, as we remember and retell our experiences. A second strategy takes a more fine-grained approach, stepping back from a grand theory of narrative to focus instead on the micro-structures of narrative, the process by which questions are repeatedly posed and then answered in order to sustain viewer interest and move the overall narrative ahead. Rather than thinking of narrative as an overarching structure of the entire experience (whether Aristotle's or Freytag's 'beginning, middle, and end'), it can instead be understood as the building blocks of an experience, each with its own cycle of 'exposition, transformation, and resolution'.

Storytellers are quite adept at keeping us on the edge of our seats with this technique, interweaving mini-narratives as a means of establishing the characters, settings, and events that will constitute the overall narrative. From this perspective, certain forms of the interactive narrative- such as the interactive documentary or interactive literature-simply disaggregate these 'mini-narratives' from one another, allowing the viewer to reassemble them in a manner that suits her interest. The basic DNA of the narrative-the sequence-stays intact, while the larger assembly process is open to user modification. A third and more radical approach argues that narrative is part of our psychological armature, a way of seeing, rather than a character of the text. Best known as cognitive narratology, here, narrative describes a way of encountering the world, an organizing experience, an existential gestalt (Herman 2009). Created and experienced on the fly, it is situational and does not have to await post facto retelling or the aggregation of mini-narratives in order to constitute a narrative experience. Rather, it manifests itself in the perception of coherence and linkage among experienced events. The various claims to support the interactive documentary's narrative status can be found within this spectrum of arguments. 
Of course, more than mere argument supports one or another of these approaches to narrative. Interactive documentaries come in many different forms, some of their textual structures adhering rather closely to long established narrative traditions; others, explicitly taking the form of mini-narratives that the user can move among and link; and still others offering rich if disaggregated possibilities to the motivated participant, who can connect the dots into a narrative experience. Some projects (Alma: A Tale of Violence, Dewever-Plana and Fougère 2012 is a strong case; Bear 71 , Mendes and Allison 2012, a weaker one) are essentially retellings of past events and lead inexorably to certain fixed conclusions, despite the fact that users may navigate multiple routes to that end state. These forms share qualities of the traditional narrative (a definite story arc based on past events, a narrator), even as they encourage excurses and wandering. Others (Planet Galata - A Bridge in Istanbul, Thalhofer and Bas 2010; Question Bridge: Black Males, Johnson et al. 2012) require the user to wander and navigate at their own pace, exploring the spaces, characters, and issues that they find interesting. The makers have made choices about what to include and offer structures to help shape and lend coherence to the user experience, but there is no preordained conclusion or story arc other than that conjured up by the user. Another, perhaps more extreme example may be found with 18 Days in Egypt (Mehta and Elayat 2011), which offers a database of crowd-sourced mini-documentaries, tagged with minimal metadata, so that users can follow a particular maker or topic. Although quite fragmented, coherence in this case emerges from the pro-filmic event (the 18-day long revolution whose symbolic center was Cairo in 2011 and its aftermath) and the interface design, enabling motivated users to move among the many differently authored shards of still and video documentation and emerge with a rich multi-perspectival view. Like Question Bridge and Planet Galata, the onus is on the user to make sense of what is encountered; unlike them, the dispersed nature of the event coupled with the very different voices and styles of representation it includes (and the minimal metadata and guidance) requires greater levels of user motivation to work through the database.

The space between Sonnen and Osterweil's analogies of 'wandering' and 'play' is a fruitful one as we consider the ongoing development of interactive forms. One of the reasons that some documentary makers - rather than fiction makers-have so quickly adopted these new techniques is that in many cases, users already know the neighborhood in which they will wander and play. Users' pre-existing familiarity with 'reality' provides ample context and motivation for them to explore interactive options and have them cohere as a unified and meaningful experience. In a fictional setting, by contrast, 
the diegetic frame must first be established before users can meaningfully wander around the story world - something we can see from game design. In either case, the structure of the textual environment bears heavily on the nature of the user experience; just as the perception of narrative depends heavily on the user's affect. Sonnen's sense of 'wandering' makes great sense for non-fiction: we, the wanderer, are oriented, have some sense of our setting, and go on to explore it. As stated, 'reality' provides a sufficient context and motive. By contrast, Osterweil's notion of 'play,' peopled with invented or assumed characters who are rule-bound by the conceits of the game, makes great sense for fiction. But it costs time and energy to establish these invented characters, to delineate the basic contours of the fictional world and its operating rules. The threshold for the 'player' would seem to be higher than for the 'wander.' And yet, to restrict the player to fictional worlds would be to impoverish non-fiction, denying it imaginative and invented entry points and characters (as if a purely objectivist stance were even possible!).

We have only to look back on the 'official history' of our documentary tradition, which begins in 'creative interpretation,' as John Grierson's 1926 review of Flaherty's Moana reminds us. Several generations of documentary historians jumped on the bandwagon, underscoring the point by simply dismissing as 'naïve' the hyper-realist renderings of cities, factory processes, and peoples that dominated non-fiction from 1895 until the early 1920s, and embracing Flaherty's story conventions. This is a troublesome view, not because of its acceptance of an expansive vocabulary and notion of imaginative engagement, but rather for its exclusion of a rich representational tradition rather akin to wandering, one, moreover, that stands as the culmination of several ways of seeing in the late nineteenth century. That said, Moana's invented characters, like those of Nanook of the North (1922) before it and generations of documentaries after, remind us that the fiction / non-fiction divide is not quite as clean as some would like it to be. And Osterweil's notion of the player goes one step farther, reminding us that meaningful invention need not only manifest itself in on-screen fictions, but rather can infuse our way of seeing as we walk through — and play in-a world. That is, rather than (like Flaherty) fictionalizing elements of the pro-filmic world in order to sharpen insights into its operations, being 'in character' allows us to bring a new vantage point to the world that we are exploring, to see it with new eyes, to engage it with an assumed agenda. One of the great potentials of interactive documentary is the flexibility that it affords the user to find her way through a constructed environment. That one can do this 'in character' would seem to provide ways of discovering 
new aspects of the world, of engaging with it in fresh ways, rather than simply seeing the world through the eyes of the other in the form of the maker of a linear film. Instead, as in the act of playing (rather than listening to the story told), we have the opportunity to assume a set of instincts, to invent a viewing position, and to enact it, respond through it, and in the process, learn.

Today's interactive documentary caters to the wanderer, and with wonderful effect. But it has an as-yet-underutilized capacity to address the player. For this to happen will require more than the efforts of documentary makers: we also have to do our part, and re-learn the art of abandoning ourselves to imagined roles, to the assumed rules and goals of a narrative conceit, and to 'play' our way through documentary environments.

\section{Engagement}

Over the past decade or so, 'engagement' has become an oft used term in the worlds of marketing and audience metrics, indicating a shift in interest from the mere 'exposure' of audiences to texts, to the quality of the audience's experience. Although initially presented by qualitative researchers as a challenge to a media industry built upon counting eyeballs and clicks, it has gained traction, encouraged by the rapid state of media change and the evident need for new perspectives. The internet as well as computer games, e-readers, and digital television all share potentials for user interactivity as well as data tracking, offering a quantitative underpinning to qualitative concerns, and helping to drive an emerging paradigm shift in institutional notions of audience participation.

This broad shift serves as a backdrop for the operations of the interactive documentary, which seems to promise enhanced opportunities both for user engagement and-especially for the funders of social impact documentary — for measuring something that might be interpreted as such. Among such 'engagement-inducing' activities we can distinguish: crowd-sourced funding to support particular documentary initiatives; crowd-sourced footage and community co-design; user-determined routings through textual environments; and the 'after-life' of projects that remain as active platforms for ongoing community interaction. Of course, not all of these are unique to the digital domain: crowd-sourced funding and sourcing, co-design, and even the community-based 'afterlife' of projects all have analog precedents. But the digital domain greatly facilitates these practices, and has the added value of making their operations in some senses more visible. 
There is much here that we do not know. For example, are contributors to crowdfunding initiatives (say, Kickstarter or JuntoBox, which offer ways to fund projects without promising the funder any ownership of the project or revenues from it) more likely to feel engaged? Since this is a self-selecting group, contributing resources on the basis of interest, the answer is presumably 'yes' - they were engaged as a condition of giving to the project. But how, beyond funding, might this manifest itself? Might they draw in their circle of friends? Promote the project and its cause in a personal way, encouraging others around them to share their interest? Might they, in other words, take a more active role in proselytizing the project, thereby having a social stake in its use, than a non-involved participant? The same might be asked of people who contribute footage to a crowd-sourced initiative, such as Perry Bard's 2007 and ongoing Man with a Movie Camera: The Global Remake project (which offers remixes of user-generated footage to remake Vertov's film every day), or Kevin Macdonald's 2011 Life in a Day (which drew from 80,000 YouTube submissions). While the act of submitting footage presumes a high level of engagement, does this, in turn, lead to ongoing efforts to engage a larger cohort of participants and viewers to the project? I am unaware of detailed evidence regarding these behaviors; but the amplification logics of social media are increasingly well studied, and may offer an appropriate analogy for these behaviors.

Collaborative documentaries also avail themselves to forms of co-design. This established practice, dating back at least to the 1970s, is related to user-centered design and participatory design (although it does not presume that any stakeholder is more relevant than another). It is process-oriented, blurring the roles of designer and author, much as some documentary projects blur the roles of author and user. Co-design developed with the notion that better designs emerge from directly involving stakeholders in the design process; so, it seems reasonable to draw on this tradition if we want to enhance engagement, involving stakeholders in the documentation process. An example of such an approach is the cross-platform project Sandy Storyline (Premo, Falcone, and Gottesdiener 2012), described by Tribeca's Ingrid Kopp as "a community-generated narrative of the storm that seeks to inspire a safe and more sustainable future. [...] It creates a living archive that shows the potential for sharing stories on a very human scale" (2012). Organized by members of the social justice movement, Sandy Storyline's avowed goal is to foster civic dialog so communities can decide, from the ground up, their own futures. Sandy Storyline, like Hollow: An Interactive Documentary (McMillion 2013) - an initiative "for the community, by the community," is deeply embedded in the lives of those who are its co-producers. Hollow uses video 
portraits, user-generated content, photography, soundscapes, interactive data, and grassroots mapping not just to document a community's past, but to play an active role in building its future. Although both projects are, as of this writing, quite new, they have no 'end' in sight, serving as ongoing, growing, and dynamic resources for their participants, who continue to contribute imagery and comments. Less of an 'artifact' (in the sense that films tend to be once completed and shown) than an ongoing forum for documentation, reflection, and exchange, projects like Sandy and Hollow point to a new and largely unexplored dimension of the 'new' documentary to which we need to attend. Their civic character holds great potential, providing ways for communities to share knowledge and experience, and offering citizens incentives for sustained participation.

As noted, one can certainly find precedents in the analog past for these incentives to engagement, such as Britain's 1930s Mass Observation Project that involved thousands of citizens for its findings (Sheridan 1993). But the affordances of networked computers and digital cameras have greatly lowered the barriers to participation and enhanced a two-way dialog between project developers and the public. As alluded to in the previous section on narrative, the interactive character of these documentaries, their requirement that the user 'wander' or 'play,' adds a distinctive opportunity to engage by making participants co-constructors of the text itself, rather than 'mere' readers. The user's interests presumably direct the process of negotiation through the documentary environment. While we can surmise that the ensuing textual experience differs from encounters with ready-made texts, like storytelling differs from play in Osterweil's terms, the nature of that difference and its implications for user engagement — as in the other cases—remains under researched and unknown. We do know that in some digital environments, users leave traces, allowing designers to discern behavioral patterns. Traces may offer evidence of engaged behaviors; and perhaps more importantly, they may offer insights into barriers to participation, points that could be redesigned or tweaked in some way in order to encourage more sustained participation. Because there is no fixed text, but rather a textual environment ripe with narrative possibilities, producers can continually refine the project, responding to aggregated behaviors and user feedback. Like the long 'afterlife' of some projects, this ability to continually fine-tune an interactive documentary in response to user behaviors offers a potentially new and powerful dimension for exploration. 


\section{Looking ahead...}

Mobile telephony did not initiate distant communication, but it certainly enabled us to redefine fundamentally our notion of being connected. Indeed, the mobile phone's potential to connect us anytime and anywhere seems to have acquired a new sense of urgency, at least for those of us who carry one, most evident in the panic that sets in with forgotten phones or dead batteries. Moreover 'connection,' in the age of the smart phone, has come to mean far more than the potential to reach others or be reached by them. It entails experiential forms and cultural logics once relegated to distinctive media practices. It means being always connected to one's favorite music, photos, and books; connected to geo-locative information and spatially oriented; connected to email and online social networks; connected to the world through an ability to share experience through live-streamed and recorded audio and video. This conflation of once separated media practices, both enabled by technology and embodied in our everyday enactments, is familiar from the computer and examples across nearly every other digital platform (cameras that can also send images, e-books that play music, etc.). And this remix of our media practices, sensibilities, and opportunities, is fundamental to the new turn in documentary.

As noted at the outset, conditions such as the widespread penetration of cell phones, many equipped with HD video cameras, and those that are not, still enabled to carry out the work of documentation thanks to software systems like Vojo and Vozmob or Mobile Voices/Voces Móviles, ${ }^{8}$ have shifted the locus of representation. The ability to record and transmit image, sound, and data such as location, is now in the hands of that 102.2 per cent of the (in this case, American) public equipped with mobile phones. The intertwining of recording and transmitting systems, the ease of access to web-based aggregating systems (whether live streaming sites such as Qik and USTREAM or aggregators of recorded material like YouTube) and elegantly simple story assembly tools (such as Zeega, Cowbird, and Storyplanet), have all empowered that public to take the next step, and tell their own stories. And, in cases like Sandy Storyline, 18 Days in Egypt, and the many stories aggregated on Cowbird, they have done so. At the same time, the more active stance encouraged by these new affordances (not to mention, the daily realities of negotiating the internet and portals such as YouTube or sites such as Facebook) has also encouraged people to navigate

8 Vozmob provides a platform for immigrant and/or low-wage workers to create stories about their lives and communities directly from simple cell phones. 
their own way through the audio-visual environments provided by others, in the process creating their own experiences and stories. Here, too, the quotidian status of the smart phone has not only made trivial the process of textual construction, but has greatly expanded the space of reception. We can view and interact with this material virtually anywhere that we can receive a signal; and thanks to geo-location technologies, documentaries can potentially be viewed in situ, interacting with the spaces and places that they document.

The implications of these shifts from over a century of professionalized documentary production and institutionalized sponsorship, distribution, and exhibition, are just beginning to be felt. On one hand, some professionals and institutions have reached out to the public, embracing them as partners in the project of collaborative documentation, as can be seen in the work of the National Film Board of Canada with Kat Cizek's Highrise series (2010) or Hugues Sweeney's A Journal of Insomnia (Duverneix et al. 2013). And on the other, as noted with Sandy Storyline and the many projects enabled through Vozmob, activists and the public have found ways to make their voices heard largely outside the domain of professional and institutional practices. Add this to the changes already noted - the destabilization of the fixed text, the challenge to the authority of the author, and new roles of contributor and collaboration taken up by the public, and the contours of the situation seem both new... and familiar. This shift from a limited, centralized, institutional discourse to an open, decentralized, and participatory process is familiar in the network age. Similar transformations might be condensed into the 'Encyclopedia Britannica/Wikipedia' dynamic: one, carefully vetted, attributable, and stable; the other, open, more or less self-regulating, and dynamic. Each have important affordances, but the shift from an institutional monopoly to a pluriform and open environment requires a perceptual shift. Faith in institutional vetting and the cult of expertise is no longer sufficient grounds (as if it ever were!) to navigate the world. Instead, the onus is on users to develop a critical stance, to assess, compare, and be open to contingencies. At this moment of regime change in the domain of representation, rather than fixating on a notion of unassailable truth (or lamenting its passing), we need to demand transparency, and to bring our critical judgment to bear, rather than relying on faith in-or giving obeisance to-a higher authority.

Like Sonnen's reference to wandering in the city versus taking a guided tour, or Osterweil's notion of play versus listening to a great storyteller, participation and collaboration in the representation of reality will exist alongside our long reliance on hierarchies of expertise. This is not a situation 
of either/or, of the well-authored, carefully crafted, and institutionally endorsed documentary versus its user-negotiated, participatory, and grassroots counterpart. Rather, it is a tale of different affordances and, more importantly, of the emergence of a new and critical stance. The appearance of a new art of documentary, though still finding its way, has necessarily recontextualized the long (and still) dominant tradition. And with that recontextualization, we can expect the critical reception practices required in the participatory age to bleed into even the most vetted and institutionally endorsed of documentary productions. In this sense, Sonnen's and Osterweil's heuristic binary opposition might well be complicated by unruly tours and playful listeners, practices that, repositioned within the civil society, add up to responsible citizenship.

\section{Acknowledgments}

This chapter is based on a manuscript written in 2013.

\section{References}

Anderson, T., M. Blank, D. Lebling, and B. Daniels. 1977. Zork. [PDP-10]. Game. Aston, J., and S. Gaudenzi. 2012. Interactive documentary: Setting the field. Studies in Documentary Film 6 (2): 125-139.

Bard, P. 2007. Man with a Movie Camera: The Global Remake. A Bigger Picture Commission Art. Film project.

Cizek, K. 2010. Highrise/Out My Window. NFB Interactive. Multimedia project. Činčera, R., J. Lihny, and M. Hornícek (dir.). 1967. Kinoautomat. Film.

Dewever-Plana, M., and I. Fougère (dir.). 2012. Alma: A Tale of Violence. Upian.com. Film.

Duverneix, T., B. Choiniere, P. Lambert, and G. Braun (dir.). 2013. A Journal of Insomnia. National Board of Canada. Film.

Edmond, M. 2015. All platforms considered: Contemporary radio and transmedia engagement. New Media \& Society 17 (9): 1566-1582.

Flaherty, R. J. (dir.). 1922. Nanook of the North. Pathé Exchange. Film.

- 1926. Moana. Paramount Pictures. Film.

Galloway, D., K. B. McAlpine, and P. Harris. 2007. From Michael Moore to JFK Reloaded: Towards a working model of interactive documentary. Journal of Media Practice 8 (3): 325-339.

Grierson, J. Review: Moana. The New York Sun. 8 February 1926. 
Herman, D. 2009. Cognitive narratology. Handbook of narratology 19:30. Jenkins, H., S. Ford, and J. Green. 2013. Spreadable media: Creating value and meaning in a networked culture: New York: NYU Press.

Johnson, C., H. W. Thomas, B. R. Smith, and K. Sinclair (dir.). 2012. Question Bridge: Black Males. Bay Area Video Coalition. Film.

Kopp, I. 2012. Sandy Storyline. Tribeca Film Festival film guide archive. http://tribecafilm.com/filmguide/archive/51424e82co7f5db7a6ooooo c-sandy-storyline.

Lessig, L. 2015. Free culture. Lulu.com.

Macdonald, K. (dir.). 2011. Life in a Day. National Geographic Film. Film.

Marsh, T., C. Xuejin, L. Nickole, S. Osterweil, E. Klopfer, and J. Haas. 2011. Fun and learning: The power of narrative. In Proceedings of the 6th international conference on the foundations of digital games, Bordeaux, June 28 - July 1, 2011, 23-29. New York: ACM.

McMillion, E. (dir.). 2013. Hollow: An Interactive Documentary. Multimedia. Mendes, J., and L. Allison (dir.). 2012. Bear 71. National Film Board of Canada. Film.

Mehta, J., and Y. Elayat (dir.). 2011. 18 Days in Egypt. GroupStre.am. Film.

MIT Open Documentary Lab. 2018. MIT: Moments of innovation. MIT. http:// momentsofinnovation.mit.edu.

Moore, K. 2011. 71\% of online adults now use video-sharing sites. Pew Research Center. http://www.pewinternet.org/Reports/2011/Video-sharing-sites.aspx.

Nichols, B. 1991. Representing reality: Issues and concepts in documentary. Bloomington, IN: Indiana University Press.

Premo, M., R. Falcone, and L. Gottesdiener (dir.). 2012. Sandy Storyline. Multimedia.

Ruttman, W. (dir.). 1929. Melodie der Welt. Tobis Filmkunst. Film.

Saunders, D. 2007. Direct cinema: Observational documentary and the politics of the sixties. London: Wallflower Press.

Sheridan, D. 1993. Writing to the archive: Mass-observation as autobiography. Sociology 27 (1): 27-40.

Singer, B. 1987. Connoiseurs of chaos: Whitman, Vertov, and the poetic survey. Literature/Film Quarterly 15 (4): 247.

Statistic Brain. 2016. STATS: Youtube company statistics. Statistic Brain Research Institute. http://www.statisticbrain.com/youtube-statistics.

Thalhofer, F., and B. Bas (dir.). 2010. Planet Galata: A Bridge in Istanbul. Kloos \& Co. Film.

Trettien, W. A. 2009. Computers, cut-ups and combinatory volvelles: An archaeology of text-generating mechanisms. MA Thesis: Massachusetts Institute of Technology. 
Uricchio, W. 2011. A 'proper point of view': The panorama and some of its early media iterations. Early Popular Visual Culture 9 (3): 225-238.

Vertov, D. (dir.). 1929. Man with a Movie Camera. VUFKU. Film.

-.1931. Enthusiasm. Ukrainfilm. Film.

\section{About the author}

William Uricchio is Full Professor of Comparative Media History at Utrecht University as well as Full Professor of Comparative Media Studies at MIT. He was principal investigator of the Singapore-MIT GAMBIT Game Lab, and at MIT he is founder and principal investigator of the MIT Open Documentary Lab. He is (co-)author or (co-)editor of several books including Reframing culture: The case of the Vitagraph quality films (Princeton University Press 1993) and We Europeans? Media, representations, identity (University of Chicago Press 2009). Uricchio is series editor (along with Jesper Juul and Geoff Long) of the MIT Press Playful Thinking Series on game related topics. His scholarly research considers the interplay of media technologies and cultural practices in relation to the (re-)construction of representation, knowledge, and publics. His current research focuses on forms of augmented reality and the cultural use of algorithms. 